\title{
Factors Influencing Purchase Intention on Mobile Shopping Web Site in China and South Korea: An Empirical Study
}

\author{
Xuan WEN, Yiran LI, Cong YIN
}

\begin{abstract}
The research objective of this study is to analyze the factors that influence consumers' perceptions of using mobile commerce services for online shopping in China and South Korea using ordered logistic regression analysis. We constructed the research model using the three dimensions of individual characteristics, shopping motivations and the characteristics of mobile shopping. We discovered that shopping frequency, utilitarianism, instant connectivity, and personalized information push positively impact the customers' intention to use mobile phones in China. The results of the marginal effects indicated that the behavioral intentions of Chinese consumers increased when shopping frequency and instant connectivity increased. In addition, when utilitarianism and the personalized information push reach certain values, the shopping intention of online customers in China will decrease. Likewise, shopping frequency, hedonism, utilitarianism, instant connectivity, and SNS (Social Networking Services) accessibility positively affect the intention to use the Internet for $\mathrm{m}$-shopping of South Korean consumers. In addition, the results regarding the marginal effects suggested that the intention to use m-shopping services on m-shopping web site of South Korean consumers increased as shopping frequency, hedonism, and instant connectivity increased. However, South Korean consumers' adoption intention will decrease when utilitarianism and SNS accessibility reach certain values. These results provide important implications for mobile commerce literature and practice.
\end{abstract}

Keywords: China and South Korea; mobile shopping; ordered logistic regression analysis; purchase intention

\section{INTRODUCTION}

China and South Korea are the most important mobile commerce markets in Asia. The economic and trade exchange flows are active in both countries. With the rapid development of mobile communication technology, the new purchase patterns that occur due to mobile shopping (m-shopping) have subtle influences on consumers' shopping habits.

According to the 2017-2018 China Mobile ECommerce Industry Research Report by Iimedia, in 2017, the number of mobile phone users reached 473 million, and this number is expected to reach 512 million by 2018 [1]. The consulting analysts of Iimedia believe that there is still extensive space for the development of mobile commerce. According to the China Internet Network Information Center (CNNIC), as of December 2017, the number of online shoppers in China reached 533 million, which is an increase of $14.3 \%$ from 2016 and is $69.1 \%$ of the total number of Internet users. Furthermore, the online retail industry continued to grow at a high rate with an annual turnover of 719.51 billion yuan, which is an increase of $32.2 \%$ for the same period in the previous year and an increase of $6 \%$ percentage points from 2016 [2].

Similar to the development model of China's mobile commerce market, the mobile commerce market of South Korea has also experienced a period of explosive growth. According to Statistics South Korea, the volume of online shopping transactions reached 8 trillion won, which was $22 \%$ more than the previous year. Meanwhile, the shipments of online shopping sites reached 5 trillion won, which was $33.6 \%$ more than the previous year [3]. The rapid expansion of the South Korean mobile commerce market has benefited from the high penetration rate of smartphones and the improvement of network communications. Furthermore, social commerce and open markets have become key components of m-shopping. The major groups in the South Korean mobile commerce market are young people between the ages of 20 and 30, while people between the ages of 40 and 50 also have experienced a rapid increase [4].

Within this context, studying the influencing factors of consumers' intention to engage in m-shopping has important referential value for Chinese and South Korean marketers to maintain their advantages under the current fierce competition. So far, there are too many researchers that have used the technology acceptance model (TAM), and fewer have adopted ordered logistic regression analysis to explore customers' intention. A previous study found that the technical characteristics of external factors and the personal characteristics of internal factors importantly affect the behavioral intention to use $\mathrm{m}$ shopping service $[5,6]$. The TAM predicts and interprets consumers' acceptance of information systems based on technical characteristics, namely, the usefulness and ease of use, while ignoring personal characteristics, such as individual characteristics and shopping motivations [7]. However, the ordered logistic regression analysis can compensate for small sample size and can make the parameter estimation results more persuasive. Therefore, this study explored the factors that influence consumers' behavioral intention to m-shopping in China and South Korea using ordered logistic regression analysis.

M-shopping has its own unique characteristics and advantages. Consumers are faced with mobile screens and a lack of face-to-face contact with marketers compared with traditional physical store shopping or online shopping. M-shopping apps have become important channels for consumers to search for products. Thus, the characteristics of m-shopping will affect consumers' purchase intention [8, 9]. In addition, other studies have shown that consumers' personality traits (such as age, gender, and consumption behavior) importantly impact their purchase intention [5]. Based on the above situation, this study explores the influencing factors of consumers' behavioral intention to use mobile services in China and South Korea based on three aspects: personal characteristics, shopping motivations and the characteristics of mobile shopping. 


\section{LITERATURE REVIEW}

As a derivative of mobile commerce, m-shopping is increasingly prevalent and has become a necessary part of consumers' daily lives. The research on m-shopping has been extensive and deep.

Some scholars researched the perspective of consumers' subjective feelings. A survey conducted by Dwivedi et al. in India and Mumbai demonstrated that perceived pleasure plays a key predictive role in determining consumers' adoption of mobile commerce applications [10]. Kalinic and Marinkovic developed a TAM model and verified that perceived usefulness and perceived ease of use positively impact consumers' intention to accept mobile commerce [11]. Based on the extended theory of planned behavior, Yang found that perceived pleasure is the most important factor affecting attitude [12]. Lu et al. demonstrated that ubiquitous perception, perceived personalization, and perceived risk have significant impacts on consumers' adoption of mobile shopping [13]. Liu and Tang showed that perceived usefulness, perceived ease of use, emotional experiences, and perceived value all have significant impacts on behavioral intention to m-shopping [14].

Compared with subjective feelings, factors such as trust, concerns about payment security, and brand preferences also play important roles in the stable development of mobile shopping. Kao established a research framework based on the BATE model and cultural dimensions and found that transaction trust has a significant impact on consumers' adoption of mobile shopping and which culture plays a regulatory role [15]. By exploring the factors affecting consumers' mobile shopping purchase intention in Germany (a developed market) and Peru (a developing market), Cleff et al. found that Peruvians are more susceptible than others and have higher data protection and transaction security requirements [16]. Maity compared the consumer behaviors in three sales channels: mobile commerce, e-commerce, and physical stores. He found that consumers usually use previous experience to form their decision-making basis for future purchases in mobile commerce [17]. Jang used three factors of mobile commerce (interactivity, convenience, and interest) as independent variables and price sensitivity and brand loyalty as adjustment variables to explore the impacts of these factors on consumers' mobile shopping purchase intention [18].

In summary, in the studies on the consumers' intention to engage in online $\mathrm{m}$-shopping, there are many studies on the subjective feelings, but little literature has assessed personal characteristics, shopping motivations and the characteristics of mobile shopping. Most of the studies focus on the single perspective of the consumer's subjective feelings regarding m-shopping, and fewer studies focus on the dual perspectives of personal characteristics and the characteristics of mobile shopping. Furthermore, few studies have adopted ordered logistic regression analysis to study the consumers' intention to use $\mathrm{m}$-shopping services on $\mathrm{m}$-shopping web site. To this end, this study focuses on personal characteristics, shopping motivations and the characteristics of mobile shopping; uses Chinese and Korean consumers as research objects; and adopts ordered logistic regression analysis to explore the influence mechanism of customers' intention to engage in m-shopping.

\subsection{Shopping Motivations}

Tauber believed that consumers are not only shopping for the utilitarian value of products but also for satisfaction in the purchasing process [19]. Based on Tauber's research, some scholars have found that hedonistic consumption is related to product experiences [20, 21]. Hedonistic consumers pay more attention to the entertainment experience when searching for products [22]. Hedonistic motivation can be obtained through the fun, fantasy, entertainment and enjoyment that are generated during the shopping process [23].

Utilitarian motivation is a kind of rational psychological activity related to tasks [20, 24, 25]. Scholars who hold this view regard consumers as rational problem solvers and believe that consumption is actually a means of achieving "predetermined goals" [26]. In the shopping process, consumers usually adopt a rational attitude to find products with utilitarian value that meet their expectations [21, 27]. Utilitarian consumer behavior is often related to rational cognition. Therefore, this study uses hedonism and utilitarianism as measures of shopping motivations.

\subsection{Characteristics of Mobile Shopping}

Mobile shopping is a trading pattern in which people realize monetary value through mobile communication networks $[28,29]$. It can be said that mobile shopping has driven fundamental changes in many industries. It enables consumers to access web information services and purchase goods at any time and anywhere, namely, instant connectivity [30-33]. Thus, we selected instant connectivity as the first characteristic of mobile shopping in this study.

Table 1 Previous studies by Chinese and South Korean scholars on the characteristics of mobile shopping

\begin{tabular}{|c|c|c|c|c|c|c|c|}
\hline \multicolumn{4}{|c|}{ China } & \multicolumn{4}{|c|}{ South Korea } \\
\hline Gu et al. [40] & Zhang [41] & Lu et al. [13] & Hua et al. [42] & Ko et al. [43] & Lee [44] & Jang [18] & Heung [45] \\
\hline Mobility & Ubiquity & Ubiquity & $\begin{array}{l}\text { Fast network } \\
\text { environment }\end{array}$ & Utility & Instant connection & Interactivity & Interactivity \\
\hline Instantaneity & Personalization & Individualization & $\begin{array}{c}\text { Rich business } \\
\text { content }\end{array}$ & Enjoyment & Mobility & Convenience & $\begin{array}{l}\text { Information } \\
\text { provision }\end{array}$ \\
\hline Privacy & Elasticity & $\begin{array}{l}\text { Situational } \\
\text { provision }\end{array}$ & $\begin{array}{c}\text { Safe payment } \\
\text { channels }\end{array}$ & Easy-to-use & Personalization & Interest & Easy-to-use \\
\hline Convenience & Transmission & & $\begin{array}{l}\text { Personalized user } \\
\text { experience }\end{array}$ & $\begin{array}{c}\text { Instant } \\
\text { connection }\end{array}$ & $\begin{array}{c}\text { Social } \\
\text { communication }\end{array}$ & & \\
\hline
\end{tabular}


The personalized information push is one of the most important characteristics of mobile shopping [34] Marketers can increase their sales by providing consumers with personalized marketing information based on their personal preferences and location [35].This suggests that personalized information push can affect consumers' purchase decisions. Hence, we selected personalized information push as the second characteristic of mobile shopping in this study.

Social media redefines personal lifestyles and business activities $[36,37]$. It is an online repository that enables consumers to create, discover, and share product information [38]. Companies can leverage social platforms for better marketing and customer relationship management [39]. The easy accessibility of SNS applications to mobile shopping applications is an important part of ensuring the effectiveness of mobile social commerce. Therefore, we selected SNS accessibility as the third characteristic of mobile shopping in this study. We reviewed and summarized the research on the characteristics of mobile shopping by Chinese and Korean scholars in Tab. 1.

\section{RESEARCH METHODOLOGY 3.1 Research Model}

The research investigates the effects of various factors on customers' intention to use m-shopping services. We proposed a research model with the three dimensions of individual characteristics, shopping motivations and the characteristics of mobile shopping. Individual characteristics include gender, age, daily use time of mobile phones, shopping frequency, and monthly consumption. The shopping motivations include both hedonistic and utilitarian dimensions. The characteristics of mobile shopping include instant connectivity, the personalized information push, and SNS accessibility. The research model is presented in Fig. 1.

This study adopts 10 independent variables as explanatory variables $(X)$ and 1 index of mobile shopping intention as the explained variable $(Y)$ for the parameter estimation. The measurement of the variables is shown in Tab. 2.

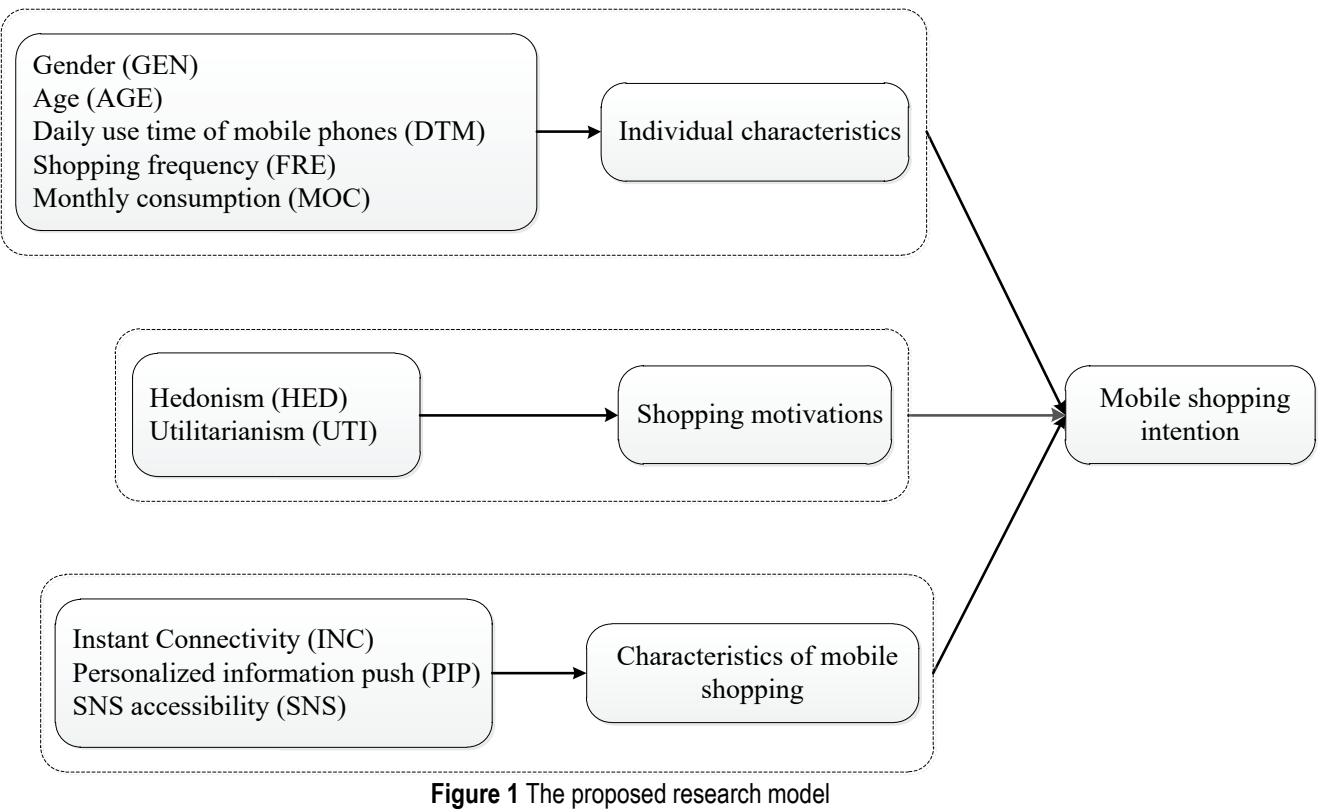

The cumulative probability expression of the independent variables in the ordered logistic regression model is as follows:

$$
P(Y \leq j \mid \underline{x})=F_{j}(\underline{x})=\pi_{1}(\underline{x})+\ldots+\pi_{j}(\underline{x})
$$

Where $\pi_{j}(\underline{x})$ is the response probability of the $j$ indicator of the explanatory variable $X$. The cumulative logits expression for each indicator $\mathrm{j}$ is as follows:

$$
L_{j}(\underline{x})=\ln \left[\frac{F_{j}(\underline{x})}{1-F_{j}(\underline{x})}\right], j=1,2, \ldots,(c-1),
$$

The expression of using all accumulated logits in one model is as follows:

$$
\hat{L}_{j}(\underline{x})=\hat{\alpha}_{j}+\underline{\hat{\beta}}^{\prime}{ }_{j} \underline{x}
$$

Each cumulative logit has an intercept, namely, $\hat{\alpha}_{j}$. The $\hat{\alpha}_{j}$ increase as the $\mathrm{j}$ increases. $P(Y \leq j \mid \underline{x})$ will also increase as the $j$ increases when the value $x$ is constant. $\hat{\alpha}_{j}$ and $\underline{\hat{\beta}}^{\prime}$ are the maximum likelihood estimations of $\hat{\alpha}_{j}$ and $\hat{\beta}^{\prime}$. If other explanatory variables have no effect on $\hat{L}_{j}(\underline{x})$, the above estimates represent the cumulative logits of each indicator $j . \hat{\beta}^{\prime}$ is a set of regression coefficients corresponding to $\underline{x}$, which represent the cumulative logits of each indicator $j$. 
After obtaining the parameter estimates of $\hat{\alpha}_{j}$ and $\hat{\beta}^{\prime}$, the estimated value of $P(Y \leq j \mid \underline{x})$ can be worked out by the logits cumulative function, as shown below:

$P(Y \leq j \mid \underline{x})=\left[\frac{\exp \left(\hat{\alpha}_{j}+\underline{\hat{\beta}}^{\prime} \underline{x}\right)}{1+\exp \left(\hat{\alpha}_{j}+\underline{\hat{\beta}}^{\prime} \underline{x}\right)}\right], j=1,2, \ldots,(c-1)$

Or:

$P(Y \leq j \mid \underline{x})=\left[\frac{1}{1+\exp \left(-\hat{\alpha}_{j}-\underline{\hat{\beta}}^{\prime} \underline{x}\right)}\right]$

The result is obtained as follows:

$P(Y \leq j \mid \underline{x})=\left[\frac{1}{1+\exp \left(-\hat{L}_{j}(\underline{x})\right)}\right]$
In order to further analyze the changes in behavioral intentions, this study uses marginal point estimates and correlation coefficients to calculate the marginal effects in the following formula:

$$
\frac{\partial P(Y \leq j \mid \underline{x})}{\partial x}=\frac{\exp \left(-\hat{L}_{j}(\underline{x})\right) * \hat{L}_{j}(\underline{x})}{\left(1+\exp \left(-\hat{L}_{j}(\underline{x})\right)\right)^{2}}
$$

Since the marginal effect calculation method of conventional continuous variables does not apply to dummy variables, we treat all variables except for this variable as constant zeros when calculating the marginal effect of a dummy variable separately. Then, we calculate the marginal effects according to the following formula (7) (where $\mathrm{c}$ is a constant term):

$E\left[Y \mid X_{j k}=1\right]-E\left[Y \mid X_{j k}=0\right]=F_{j}(\underline{x}+c)-F_{j}(c)$

Table 2 Measurement of the independent variables

\begin{tabular}{|c|c|c|c|c|c|c|}
\hline \multirow{2}{*}{ Variable attributes } & \multirow{2}{*}{ Variable name } & \multirow{2}{*}{ Variable assignment } & \multicolumn{2}{|c|}{ China } & \multicolumn{2}{|c|}{ South Korea } \\
\hline & & & Mean & SD & Mean & SD \\
\hline \multirow[t]{5}{*}{ Individual characteristics } & Gender (GEN) & $0=$ Male $; 1=$ Female & 0.530 & 0.500 & 0.565 & 0.497 \\
\hline & Age (AGE) & $\begin{array}{c}1=\text { Less than } 20 \\
2=20-25 \\
3=26-30 \\
4=\text { Over } 30\end{array}$ & 2.305 & 0.771 & 2.140 & 0.634 \\
\hline & Daily use time of mobile phones (DTM) & $\begin{array}{c}1=\text { Less than } 1 \text { hour } \\
2=1-3 \text { hours } \\
3=3-5 \text { hours } \\
4=\text { Over } 5 \text { hours }\end{array}$ & 2.925 & 0.885 & 2.860 & 0.951 \\
\hline & Shopping frequency (FRE) & $\begin{array}{c}1=\text { At most once a year } \\
2=\text { At least Once a year } \\
3=\text { At least Once a month } \\
4=\text { At least Once a week }\end{array}$ & 3.285 & 0.637 & 2.690 & 0.870 \\
\hline & Monthly consumption (MOC) & $\begin{array}{c}1=\text { Less than } 100 \mathrm{RMB} \\
2=100-500 \mathrm{RMB} \\
3=500-1000 \mathrm{RMB} \\
4=\text { Over } 1000 \mathrm{RMB}\end{array}$ & 2.130 & 0.711 & 1.910 & 0.816 \\
\hline \multirow[t]{2}{*}{ Shopping motivations } & Hedonism (HED) & $\begin{array}{l}\text { Likert Five-level scale } \\
1=\text { strongly disagree }\end{array}$ & 3.850 & 0.923 & 3.050 & 1.420 \\
\hline & Utilitarianism (UTI) & $\begin{array}{l}\text { Likert Five-level scale } \\
1=\text { strongly disagree }\end{array}$ & 4.125 & 0.907 & 3.815 & 1.174 \\
\hline \multirow[t]{3}{*}{$\begin{array}{l}\text { Characteristics of mobile } \\
\text { shopping }\end{array}$} & Instant connectivity (INC) & $\begin{array}{l}\text { Likert Five-level scale } \\
1=\text { strongly disagree }\end{array}$ & 4.245 & 0.948 & 3.995 & 1.297 \\
\hline & Personalized information push (PIP) & $\begin{array}{l}\text { Likert Five-level scale } \\
1=\text { strongly disagree }\end{array}$ & 4.015 & 0.921 & 3.325 & 0.987 \\
\hline & SNS accessibility (SNA) & $\begin{array}{l}\text { Likert Five-level scale } \\
1=\text { strongly disagree }\end{array}$ & 3.895 & 1.009 & 3.440 & 1.026 \\
\hline
\end{tabular}

\subsection{Data Collection and Sample}

Our study adopted an offline survey of students at Wuhan University and Central China Normal University in Wuhan, Hubei province, China. We used two questionnaires versions to investigate the Chinese and South Korean respondents, respectively. The questionnaire was first designed in Chinese and then translated into Korean. To assure the reliability of the Chinese version of the questionnaire, we invited 6 e-commerce researchers whose research orientation is mobile commerce to test the questionnaire through a pilot study. The results of the pilot test were utilized to modify the structure and diction of the questionnaire. Afterward, we recruited a student major in e-commerce and two South Korean postgraduate majors in foreign Chinese to translate the modified questionnaire into Korean. In consideration of the reliability of the Korean translation, we invited 10 South Korean students to conduct a pre-test and improve the ambiguously worded items with the assistance of the two South Korean postgraduate majors in foreign Chinese. We delivered the questionnaires to Chinese and South Korean students separately. In total, 421 responses were received. After eliminating the questionnaires that had missing values and those that provided the same answers to all items, 400 valid responses are achieved with 200 Chinese questionnaires and 200 South Korean questionnaires.

As shown in Tab. 3, 53\% of the Chinese respondents and $56.5 \%$ of the South Korean respondents were female. The majority of respondents were aged between 20 and 25 
in both the Chinese and South Korean samples. Moreover, Chinese respondents spent more time daily using their mobile phones, had higher shopping frequency and spent more money per month than the South Korean respondents.

Table 3 Descriptive statistics of the respondents' characteristics

\begin{tabular}{|c|c|c|c|c|c|}
\hline \multirow{2}{*}{ Variable name } & \multirow{2}{*}{ Variable assignment } & \multicolumn{2}{|c|}{ China } & \multicolumn{2}{|c|}{ South Korea } \\
\hline & & Respondents & Proportion (\%) & Respondents & Proportion (\%) \\
\hline \multirow{2}{*}{ GEN } & $0=$ Male & 94 & 47 & 87 & 43.5 \\
\hline & $1=$ Female & 106 & 53 & 113 & 56.5 \\
\hline \multirow{4}{*}{ AGE } & $1=$ Less than 20 & 16 & 8 & 20 & 10 \\
\hline & $2=20-25$ & 129 & 64.5 & 140 & 70 \\
\hline & $3=26-30$ & 33 & 16.5 & 32 & 16 \\
\hline & $4=$ Over 30 & 22 & 11 & 8 & 4 \\
\hline \multirow{4}{*}{ DTM } & $1=$ Less than 1 hour & 10 & 5 & 10 & 5 \\
\hline & $2=1-3$ hours & 56 & 28 & 76 & 38 \\
\hline & $3=3-5$ hours & 73 & 31.5 & 46 & 23 \\
\hline & $4=$ Over 5 hours & 61 & 30.5 & 68 & 34 \\
\hline \multirow{4}{*}{ FRE } & $1=$ At most once a year & 2 & 1 & 24 & 12 \\
\hline & $2=$ At least Once a year & 14 & 7 & 44 & 22 \\
\hline & $3=$ At least Once a month & 109 & 54.5 & 102 & 51 \\
\hline & $4=$ At least Once a week & 75 & 37.5 & 30 & 15 \\
\hline \multirow{4}{*}{ MOC } & $1=$ Less than $100 \mathrm{RMB}$ & 27 & 13.5 & 69 & 34.5 \\
\hline & $2=100-500 \mathrm{RMB}$ & 132 & 66 & 87 & 43.5 \\
\hline & $3=500-1000 \mathrm{RMB}$ & 29 & 14.5 & 37 & 18.5 \\
\hline & $4=$ Over $1000 \mathrm{RMB}$ & 12 & 6 & 7 & 3.5 \\
\hline
\end{tabular}

Notes: GEN: Gender; AGE: Age; DTM: Daily use time of mobile phones; FRE: Shopping frequency; MOC: Monthly consumption.

Table 4 The results of the ordered logistic regression analysis

\begin{tabular}{|c|c|c|c|c|c|c|}
\hline & \multicolumn{3}{|c|}{ China } & \multicolumn{3}{|c|}{ South Korea } \\
\hline & Coefficient & Std. Error & Z statistic & Coefficient & Std. Error & Z statistic \\
\hline GEN & 0.220 & 0.339 & 0.648 & 0.258 & 0.318 & 0.812 \\
\hline AGE & 0.104 & 0.206 & 0.505 & 0.315 & 0.242 & 1.301 \\
\hline DTM & -0.222 & 0.195 & -1.137 & -0.302 & 0.203 & -1.483 \\
\hline FRE & $0.585^{*}$ & 0.271 & -2.157 & $0.512^{*}$ & 0.200 & -2.557 \\
\hline $\mathrm{MOC}$ & 0.465 & 0.247 & 1.879 & 0.250 & 0.120 & 1.253 \\
\hline HED & 0.082 & 0.213 & 0.388 & $0.349 *$ & 0.138 & 2.531 \\
\hline UTI & $0.798 * * *$ & 0.226 & 3.534 & $1.348 * * *$ & 0.250 & 5.397 \\
\hline INC & $0.932 * * *$ & 0.222 & 4.199 & $0.501 * *$ & 0.160 & 3.131 \\
\hline PIP & $0.667 * *$ & 0.224 & 2.983 & -0.046 & 0.225 & -0.203 \\
\hline SNA & 0.093 & 0.199 & 0.468 & $0.779 * * *$ & 0.216 & 3.604 \\
\hline \multicolumn{7}{|c|}{ Limit points } \\
\hline LIMIT_2:C(11) & 2.028 & 1.496 & 1.355 & $3.133 *$ & 1.228 & 2.552 \\
\hline LIMIT 3:C(12) & $4.287 * *$ & 1.516 & 2.827 & $4.325 * * *$ & 1.257 & 3.441 \\
\hline LIMIT_4:C(13) & $7.815^{* * *}$ & 1.581 & 4.945 & $8.310 * * *$ & 1.347 & 6.169 \\
\hline LIMIT_5:C(14) & $10.752 * * *$ & 1.664 & 6.460 & $12.308 * * *$ & 1.552 & 7.930 \\
\hline \multicolumn{7}{|c|}{ Model fitting test } \\
\hline Pseudo R-squared & \multicolumn{3}{|c|}{0.300} & \multicolumn{3}{|c|}{0.398} \\
\hline Schwarz criterion & \multicolumn{3}{|c|}{1.931} & \multicolumn{3}{|c|}{1.868} \\
\hline Hannan-Quinn criteria & \multicolumn{3}{|c|}{1.794} & \multicolumn{3}{|c|}{1.731} \\
\hline LR statistic & \multicolumn{3}{|c|}{134.043} & \multicolumn{3}{|c|}{197.902} \\
\hline Prob(LR statistic) & \multicolumn{3}{|c|}{0.000} & \multicolumn{3}{|c|}{0.000} \\
\hline Akaike info criterion & \multicolumn{3}{|c|}{1.700} & \multicolumn{3}{|c|}{1.638} \\
\hline Log-likelihood & \multicolumn{3}{|c|}{-156.039} & \multicolumn{3}{|c|}{-149.754} \\
\hline Restr. log likelihood & \multicolumn{3}{|c|}{-223.060} & \multicolumn{3}{|c|}{-248.705} \\
\hline Avg. log likelihood & \multicolumn{3}{|c|}{-0.780} & \multicolumn{3}{|c|}{-0.749} \\
\hline & \multicolumn{3}{|c|}{-} & \multicolumn{3}{|c|}{-} \\
\hline
\end{tabular}

Notes: GEN: Gender; AGE: Age; DTM: Daily use time of mobile phones; FRE: Shopping frequency; MOC: Monthly consumption; HED: Hedonism; UTI: Utilitarianism; INC: Instant Connectivity; PIP: Personalized information push; SNA: SNS accessibility.

${ }^{*} p<.05, \quad{ }^{* *} p<.01, \quad{ }^{* * *} p<.001$

\section{RESULTS}

\subsection{Measurement Models}

We used the Eviews 7.2 software to examine the validity of the Chinese and South Korean measurement models. The results of the model fitting test showed that the match of the two models was good and reliable (see Tab. 4). Meanwhile, the path coefficients and significances were displayed in Tab. 4.

The results suggested that among the individual characteristic variables, shopping frequency (FRE) had a positive effect on behavioral intention to use mobile services in both the Chinese and South Korean models. Other statistical variables were not significant.

Among the shopping motivation variables, hedonism (HED) had a positive impact on the behavioral intention to m-shopping in the South Korean model. In addition, utilitarianism (UTI) has a positive impact on the intention to engage in online m-shopping in both the Chinese and South Korean models.

The results of the characteristic of mobile shopping showed that instant connectivity (INC) and the personalized information push (PIP) positively impacted adoption intention in the Chinese model. In the South 
Korean model, instant connectivity (INC) and SNS accessibility (SNA) have positive influences on $\mathrm{m}$ shopping intention of online customers.

\subsection{Marginal Effects}

The analysis of the marginal effects of the research model was conducted using formulas (7) and (8) (Tab. 5).

The results showed that among the individual characteristic variables, shopping frequency (FRE) has increased marginal effects in both the Chinese and South Korean models. This indicates that the Chinese and South Korean consumers' intention to use the internet for mshopping will increase as their shopping frequency increases.

Among the shopping motivation variables, hedonism (HED) has increased marginal effects in the South Korean model, which suggested that the South Korean customer's intention will increase as hedonism increases. The marginal effects of utilitarianism (UTI) were the highest when $y_{i}=3$ in both the Chinese and South Korean models. This showed that the influence of utilitarianism on Chinese and South Korean customers' purchasing intention is limited. When utilitarianism reaches a certain value, the Chinese and South Korean consumers' adoption intention will decrease.

Among thecharacteristic of mobile shopping, instant connectivity (INC) has increased marginal effects in both the Chinese and South Korean models. It is therefore suggested that the Chinese and South Korean consumers' intention will increase as instant connectivity increases. In the Chinese model, the marginal effect of the personalized information push (PIP) was the highest when $y_{i}=3$. Likewise, the marginal effect of SNS accessibility (SNA) was the highest when $y_{i}=3$ in the South Korean model. This indicated that the Chinese consumers' behavioral intention to shop will decrease when the personalized information push reaches a specified value. Similarly, when SNS accessibility reaches a certain value, the Chinese customers' purchasing intention will decrease.

Table 5 The marginal effect of the independent variables on mobile shopping intention

\begin{tabular}{|c|c|c|c|c|c|c|c|c|c|c|}
\hline & \multicolumn{5}{|c|}{ China } & \multicolumn{5}{|c|}{ South Korea } \\
\hline & $\begin{array}{c}\text { Prob } \\
\left(y_{i}=1\right) \\
\end{array}$ & $\begin{array}{c}\text { Prob } \\
\left(y_{i}=2\right)\end{array}$ & $\begin{array}{c}\text { Prob } \\
\left(y_{i}=3\right)\end{array}$ & $\begin{array}{c}\text { Prob } \\
\left(y_{i}=4\right)\end{array}$ & $\begin{array}{l}\text { Prob } \\
\left(y_{i}=5\right)\end{array}$ & $\begin{array}{c}\text { Prob } \\
\left(y_{i}=1\right) \\
\end{array}$ & $\begin{array}{c}\text { Prob } \\
\left(y_{i}=2\right)\end{array}$ & $\begin{array}{c}\text { Prob } \\
\left(y_{i}=3\right)\end{array}$ & $\begin{array}{l}\text { Prob } \\
\left(y_{i}=4\right)\end{array}$ & $\begin{array}{l}\text { Prob } \\
\left(y_{i}=5\right)\end{array}$ \\
\hline GEN & -0.0012 & -0.0018 & -0.0146 & -0.0168 & 0.0345 & -0.0048 & -0.0006 & -0.0212 & 0.0007 & 0.0260 \\
\hline AGE & -0.0006 & -0.0009 & -0.0069 & -0.0079 & 0.0163 & -0.0059 & -0.0007 & -0.0259 & 0.0008 & 0.0316 \\
\hline DTM & 0.0012 & 0.0019 & 0.0147 & 0.0169 & -0.0347 & 0.0057 & 0.0007 & 0.0248 & -0.0008 & -0.0303 \\
\hline FRE & -0.0389 & -0.0033 & -0.0049 & 0.0447 & 0.0917 & -0.0096 & -0.0011 & -0.0421 & 0.0013 & 0.0514 \\
\hline MOC & -0.0026 & -0.0039 & -0.0308 & -0.0355 & 0.0729 & -0.0047 & -0.0006 & -0.0206 & 0.0006 & 0.0251 \\
\hline HED & -0.0005 & -0.0007 & -0.0055 & -0.0063 & 0.0129 & -0.0065 & -0.0008 & -0.0287 & 0.0009 & 0.0351 \\
\hline UTI & 0.0045 & 0.0067 & 0.0530 & -0.0610 & -0.1251 & 0.0252 & 0.0030 & 0.1108 & -0.0035 & -0.1355 \\
\hline INC & -0.0053 & -0.0078 & -0.0618 & 0.0711 & 0.1460 & -0.0094 & -0.0011 & -0.0411 & 0.0013 & 0.0503 \\
\hline PIP & 0.0038 & 0.0056 & 0.0442 & -0.0510 & -0.1045 & 0.0009 & 0.0001 & 0.0038 & -0.0001 & -0.0046 \\
\hline SNA & 0.0005 & 0.0008 & 0.0062 & 0.0071 & -0.0146 & 0.0146 & 0.0017 & 0.0640 & 0.0020 & 0.0782 \\
\hline
\end{tabular}

Notes: GEN: Gender; AGE: Age; DTM: Daily use time of mobile phones; FRE: Shopping frequency; MOC: Monthly consumption; HED: Hedonism; UTI: Utilitarianism; INC: Instant Connectivity; PIP: Personalized information push; SNA: SNS accessibility.

\section{DISCUSSION AND CONCLUSION}

The purpose of this study is to analyze the influencing factors of customers' perceptions of using mobile commerce services for online shopping in China and South Korea using ordered logistic regression analysis. We constructed the research model using the three dimensions of individual characteristics, shopping motivations and the characteristics of mobile shopping. The first explores the influence of the independent variables on the behavioral intentions of Chinese and South Korean consumers. The second examines the marginal effects of the independent variables. The main conclusions are as follows.

The results of the ordered logistic regression analysis showed that shopping frequency had a positive effect on m-shopping intention of online customers in China and South Korea. In addition, the marginal effects results were consistent with the above findings, which showed that Chinese and South Korean consumers' intention to use the internet for m-shopping will increase as their shopping frequency increases. This illustrates that as consumers' shopping on mobile devices increase, they will have a deeper intention to adopt m-shopping.

Our results suggest that hedonism (HED) had a positive effect on South Korean consumers' intention to engage in m-shopping, but it had no impact on Chinese consumers' adoption intention. Utilitarianism (UTI) had a positive effect on both Chinese and South Korean consumers' behavioral intentions. This means that searching for hedonistic and utilitarian value is the main reason for South Korean consumers to make a purchase in mobile commerce. Meanwhile, the results of the marginal effects also showed that their intention increases as hedonism increases. However, only Chinese consumers pay more attention to achieving utilitarian value in mobile commerce. Moreover, the marginal effect of utilitarianism suggested that the Chinese and South Korean consumers' behavioral intention to use will decrease when their utilitarianism reaches a certain value. This result demonstrates that mobile commerce may fail to meet consumers' demands when their utilitarian shopping motivations are high.

Our results also indicated that instant connectivity (INC) has a positive influence on Chinese and South Korean consumers' intention to use m-shopping services. Furthermore, as instant connectivity makes commerce more convenient, consumers will be more likely to adopt mobile commerce. The personalized information push (PIP) positively impacts Chinese customers' purchasing intention. However, the marginal effect showed that Chinese consumers will be reluctant to adopt mobile commerce when it requires a significant amount of personalized information. Furthermore, SNS accessibility (SNA) has a positive influence on South Korean 
consumers' intention. Similarly, the marginal effect showed that too much social contact will negatively affect South Korean consumers' purchasing intention.

The results provide important implications for practice. First, shopping frequency positively impacts consumers' intention to engage in online m-shopping. To enhance the customers' behavioral intention to use, marketers must accurately grasp customer demand and provide convenient purchase channels, creative sales strategies, and quality services. Second, the results showed that Chinese consumers focus more on utilitarianism for mobile commerce purchases. Marketers should take notice of the functionality of commodities and sell more utilitarian products on mobile platforms, which may be an effective way to improve the intention of Chinese consumers to adopt mobile commerce. Lastly, the personalized information push is a very important factor in enhancing the intention of Chinese consumers. However, they are unwilling to accept mobile commerce when receiving too much-personalized information. Marketers should take note of the reasonable amount of information that pushes Chinese consumers as an effective regulation method for adjusting their behavioral intentions. In addition, SNS accessibility can encourage South Korean consumers to adopt $\mathrm{m}$-shopping and, once involved, many consumers will abandon traditional commerce in order to adopt $\mathrm{m}$ shopping. Marketers should conduct a very fine balancing act between SNS accessibility and consumer attitudes in order to better understand and serve consumers.

Our study also has some limitations. First, we only select three dimensions with 10 factors for the research. There are many factors affecting consumers' intention to use mobile services, and in the future, we can select additional factors for further study. Second, we selected South Korean students from two universities in Wuhan to conduct this research. Although the data of the South Korean subjects were relatively well-acquired, the sample range may have some selectivity bias. Third, when comparing the influencing factors of Chinese and South Korean consumers' intention to engage in m-shopping, the role of culture is neglected, which may have a certain impact on the results. Further research can be carried out in the future with consideration of culture.

\section{REFERENCES}

[1] Iimedia. (2018, May 8). 2017-2018 China Mobile Ecommerce Industry Research Report. Retrieved from $\mathrm{http}: / /$ www.iimedia.cn/61300.html

[2] China Internet Network Information Center (CNNIC). (2018, March 15). The 41th Statistical Report on Internet Development in China. Retrieved from http://www.cnnic. net.cn/hlwfzyj/hlwxzbg/hlwtjbg/201803/t20180305_70249. $\mathrm{htm}$

[3] Statistics South Korea. (2018, June 4). Online Shopping Trends in April 2018. Retrieved from http://kostat.go.kr/ portal/SouthKorea/kor_nw/2/1/index.board?bmode=read\&b Seq $=\& a S e q=368248 \&$ pageNo $=1 \&$ rowNum $=10 \&$ navCount $=10 \&$ currPg $=\&$ sTarget $=$ title $\&$ sTxt $=\% \mathrm{EC} \% 98 \% \mathrm{~A} 8 \% \mathrm{~EB} \% 9$ $\mathrm{D} \% \mathrm{BC} \% \mathrm{EC} \% 9 \mathrm{D} \% \mathrm{~B} 8 \% \mathrm{EC} \% 87 \% \mathrm{BC} \% \mathrm{ED} \% 95 \% 91$

[4] DMC (Digital Media City) MEDIA. (2017, February 20). 2017 Internet Shopping Behavior and Shopper Group and Shopping Mall Analysis Report. Retrieved June 27, 2018, from http://www.dmcmedia.co.kr/notice/noticeView?dc $\mathrm{idx}=22 \& \mathrm{dn} \operatorname{idx}=632$
[5] Zheng C. D., Liu X., \& Yang X. (2012). Impact of perceived value and individual cognition on consumers' adoption intention of mobile shopping. Chinese Journal of Management, 9(10), 1524-1530.

[6] Liu, Q. H., Huang, S., \& Zhang, L.Y. (2016). The influence of information cascades on online purchase behaviors of search and experience products. Electronic Commerce Research, 16(4), 553-580. https://doi.org/10.1007/s10660-016-9220-0

[7] Liu B., Xu W., Xia H. (2018). A Study on the Continued Use Intention of Mobile Shopping from the Perspectives of Characteristics for Individuals and Applications. Journal of Management Science, 31(2), 59-70.

[8] Liu, Q. H., Zhang, X. Y., Zhang, L. Y., \& Zhao, Y. (2018). The interaction effects of information cascades, word of mouth and recommendation systems on online reading behavior: An empirical investigation. Electronic Commerce Research. https://doi.org/10.1007/s10660-018-9312-0

[9] Li K., Sun X. L., \& Yan J. Y. (2013). Factors influencing the willingness to use mobile payment system:an empirical study based on exchange theory. Management Review, 25 (3), 91-100.

[10] Dwivedi, Y. K., Tamilmani, K., Williams, M. D., \& Lal, B. (2014). Adoption of M-commerce: examining factors affecting intention and behaviour of Indian consumers. International Journal of Indian Culture and Business Management, 8(3), 345-360. https://doi.org/10.1504/IJICBM.2014.060365

[11] Kalinic, Z. \& Marinkovic, V. (2016). Determinants of users' intention to adopt m-commerce: an empirical analysis. Information Systems and E-Business Management, 14(2), 367-387. https://doi.org/10.1007/s10257-015-0287-2

[12] Yang, K. (2012). Consumer technology traits in determining mobile shopping adoption: an application of the extended theory of planned behavior. Journal of Retailing \& Consumer Services, 19(5), 484-491. https://doi.org/10.1016/j.jretconser.2012.06.003

[13] Lu, M., Cao, Y., \& Lu, Y. (2012). A Study on Consumers' Adoption of Mobile Shopping Services from a Perspective of Features in the Mobile Environment. Journal of Intelligence, 31(9), 202-206.

[14] Liu, Y. \& Tang, D. (2015). Effects of Consumer's Perceived Value on Mobile Shopping Willingness--Based on TAM and VAM models. Lanzhou Academic Journal, (4), 169-175.

[15] Kao, D. T. (2009). The Impact of Transaction Trust on Consumers' Intentions to Adopt M-Commerce: A CrossCultural Investigation. Cyber Psychology \& Behavior, 12(2), 225-229. https://doi.org/10.1089/cpb.2008.0212

[16] Cleff, T., Loris, H., \& Walter, N. (2015). Shopping On the Go - An Analysis of Consumers' Intention to Use MCommerce in Germany and Peru. Interdisciplinary Management Research, 11, 344-372.

[17] Maity, M. (2010). Critical Factors of Consumer DecisionMaking on M-Commerce: A Qualitative Study in the United States. International Journal of Mobile Marketing, 5(2), 87101.

[18] Jang, Y. D. (2015). Effects of Mobile Shopping Characteristics on Purchase Intention in a Smart Media Environment. Journal of Marketing Thought, 2(2), 60-73.

[19] Tauber, E. M. (1972). Why Do People Shop? Journal of Marketing, 36(4), 46-49. https://doi.org/10.2307/1250426

[20] Hirschman, E. C. \& Holbrook, M. B. (1982). Hedonic Consumption: Emerging Concepts, Methods and Propositions. Journal of Marketing, 46(3), 92-101. https://doi.org/10.2307/1251707

[21] Kim, B. \& Han, I. (2011). The role of utilitarian and hedonic values and their antecedents in a mobile data service environment. Expert Systems with Applications, 38(3), 23112318. https://doi.org/10.1016/j.eswa.2010.08.019 
[22] Babin, B. J., Darden, W. R., \& Griffin, M. (1994). Work and/or Fun: Measuring Hedonic and Utilitarian Shopping Value. Journal of Consumer Research, 20(4), 644-656. https://doi.org/10.1086/209376

[23] Eren, S. S., Eroğlu, F., \& Hacioglu, G. (2012). Compulsive Buying Tendencies through Materialistic and Hedonic Values among College Students in Turkey. Procedia - Social and Behavioral Sciences, 58, 1370-1377. https://doi.org/10.1016/j.sbspro.2012.09.1121

[24] Batra, R. \& Ahtola, O. T. (1991). Measuring the hedonic and utilitarian sources of consumer attitudes. Marketing Letters, 2(2), 159-170. https://doi.org/10.1007/BF00436035

[25] Liu, Q. H. \& Zhang, L. Y. (2014). Information cascades in online reading: An empirical investigation of panel data. Library Hi Tech, 32(4), 687-705. https://doi.org/10.1108/LHT-06-2014-0052

[26] Rintamäki, T., Spence, M. T., Kuusela, H., \& Kanto, A. (2006). Decomposing the value of department store shopping into utilitarian, hedonic and social dimensions: Evidence from Finland. International Journal of Retail \& Distribution Management, 34(1), 6-24. https://doi.org/10.1108/09590550610642792

[27] Carpenter, J. M., \& Moore, M. (2009). Utilitarian and hedonic shopping value in the US discount sector. Journal of Retailing and Consumer Services, 16(1), 68-74. https://doi.org/10.1016/j.jretconser.2008.10.002

[28] Carr, M. \& Hyderarbad, I. (2008). Mobile Payment Systems and Services: An Introduction. Mobile Payment Forum, 112.

[29] Au, Y. A. \& Kauffman, R. J. (2008). The economics of mobile payments: Understanding stakeholder issues for an emerging financial technology application. Electronic Commerce Research and Applications, 7(2), 141-164. https://doi.org/10.1016/i.elerap.2006.12.004

[30] Mathew, J., Sarker, S., \& Varshney, U. (2004). MCommerce Services: Promises and Challenges. The Communications of the Association for Information Systems, 14(1), 60. https://doi.org/10.17705/1CAIS.01426

[31] Qin, Z. (2010). Introduction to E-commerce. Springer Science \& Business Media.

[32] Zhang, L. Y., Zhu, J., \& Liu, Q. H. (2012). A meta-analysis of mobile commerce adoption and the moderating effect of culture. Computers in Human Behavior, 28(5), 1902-1911. https://doi.org/10.1016/j.chb.2012.05.008

[33] Kavassalis, P., Spyropoulou, N., Drossos, D., Mitrokostas, E., Gikas, G., \& Hatzistamatiou, A. (2003). Mobile Permission Marketing: Framing the Market Inquiry. International Journal of Electronic Commerce, 8(1), 55-79. https://doi.org/10.1080/10864415.2003.11044286

[34] Clarke, I. (2001). Emerging value propositions for mcommerce. Journal of Business Strategies, 25(2), 41-57.

[35] Park, C., Jun, J. K., \& Lee, T. M. (2015). Do mobile shoppers feel smart in the smartphone age? International Journal of Mobile Communications, 13(2), 157-171. https://doi.org/10.1504/IJMC.2015.067961

[36] Lam, S. S., Tao, S. S. C., Moon, K. K., Chin, E. S. K., \& Ngai, E. W. T. (2015). Social media models, technologies, and applications: An academic review and case study. Industrial Management \& Data Systems, 115(5), 769-802. https://doi.org/10.1108/IMDS-03-2015-0075

[37] Ye, Y., Zhao, Y., Shang, J., \& Zhang, L. Y. (2019). A hybrid IT framework for identifying high-quality physicians using big data analytics. International Journal of Information Management, 47(4), 65-75. https://doi.org/10.1016/j.ijinfomgt.2019.01.005

[38] Banerjee, S. \& Chua, A. Y. (2013). Customer knowledge management via social media: the case of Starbucks. Journal of Knowledge Management, 17(2), 237-249. https://doi.org/10.1108/13673271311315196
[39] Hew, J. J., Lee, V. H., Ooi, K. B., \& Lin, B. (2016). Mobile social commerce: The booster for brand loyalty? Computers in Human Behavior, 59, 142-154. https://doi.org/10.1016/j.chb.2016.01.027

[40] Gu, C., \& Ye, Y. (2004). Research on Mobile Commerce Application Based on Carriers. Modern Science and Technology of Telecommunications, (3), 38-41.

[41] Zhang, Z. (2006). Characteristics of mobile shopping and Efficiency Analysis. Shandong Textile Economy, (1), 36-37.

[42] Hua, J., Chen, C., Zheng, K., \& University, T. (2014). Research on the Influential Factors and the Demand characteristics of mobile shopping. Logistics Sci-Tech, $37(4), 1-5$

[43] Ko, E., Kim, E. Y., \& Lee, E. K. (2009). Modeling consumer adoption of mobile shopping for fashion products in South Korea. Psychology \& Marketing, 26(7), 669-687. https://doi.org/10.1002/mar.20294

[44] Lee, D.H. (2013). Smartphones, mobile social space, and new sociality in South Korea. Mobile Media \& Communication, 1(3), 269-284. https://doi.org/10.1177/2050157913486790

[45] Heung, K. Y. (2015). A Study on the Effect of Mobile Shopping Applications Features Following by Applications Preference - Mediating Effect of Price Sensitivity. Indian Journal of Science and Technology, 8(18). https://doi.org/10.17485/ijst/2015/v8i18/114870

\section{Contact information:}

Xuan WEN, PhD

(Corresponding author)

School of Information Management, Wuhan University,

No. 299 Bayi Road, Wuchang District, Wuhan City, Hubei Province, China Xuan_W113@163.com

Yiran LI, PhD

School of Information Management, Wuhan University,

No. 299 Bayi Road, Wuchang District, Wuhan City, Hubei Province, China yiran.li@whu.edu.cn

\section{Cong YIN, PhD}

Chongqing Intellectual Property School, Chongqing University of Technology, No. 69 Hongguang Avenue, Banan District, Chongqing, China cyin@cqut.edu.cn 